\title{
How relevant are vascular endothelial growth factor and intercellular adhesion molecule in the systemic capillary leak syndrome of psoriasis? ${ }^{*}$
}

\author{
Aline Lopes Bressan ${ }^{1}$ \\ Paula Mota Medeiros ${ }^{3,4}$ \\ Luna Azulay-Abulafia $^{1}$
}

\author{
Daniele Pereira ${ }^{2}$ \\ Sueli Carneiro ${ }^{1}$
}

DOI: http:/ /dx.doi.org/10.1590/abd1806-4841.20175994

\begin{abstract}
Psoriasis is a chronic disease, characterized by erythematous scaly lesions, presented in eight different forms: plaques, guttate, pustular, erythrodermic, inverse, nail and scalp psoriasis, and psoriatic arthritis. Its development depends on genetic factors, external stimulus and immune response alteration. ${ }^{1}$ Proinflammatory cytokines such as TNF-alpha, IL12 and 23 may also be involved. In the worst cases, systemic complications linked to endothelial alterations may occur. A literature review was conducted for a better understanding of what roles VEGF (vascular endothelial growth factor) and ICAM-1 (intercellular adhesion molecule) have, among other cytokines, in systemic capillary leak syndrome, involved in erythrodermic and pustular psoriasis, the most unstable forms of the disease.
\end{abstract}

Keywords: Capillary permeability; Endothelial growth factors; Endothelium, vascular; Psoriasis; Vascular endothelial growth factor, endocrine-gland-derived

\section{INTRODUCTION}

Psoriasis is a chronic inflammatory disease mediated by immune response, characterized by erythematous scaly lesions. It does not present predilection for sex and can emerge at any age. Its development is influenced by genetic factors, immune response alteration and environmental stimulus. ${ }^{1}$ Proinflammatory cytokines are released, such as TNF-alpha, IL-12 and 23. World prevalence is estimated to be 3\%, but there are no studies on this in Brazil. 20-30\% of the patients suffer from the severe form of the disease; of these, $10 \%$ of cases are associated with arthritis. The disease is considered extensive when over $10 \%$ of body surface area (BSA) is affected; thus, it has indication for systemic therapy because of potential complications. Systemic capillary leak syndrome is the complication that more frequently results in death, and often occurs from pustular and erythrodermic forms, the most unstable ones. ${ }^{1,2}$ In systemic capillary leak syndrome the endothelium is deeply involved with increased VEGF and ICAM-1, resulting in thermoregulation disorder, dehydration, tachycardia, pericardial and pulmonary effusion, respiratory distress in adults and even death. This literature review assessed the relevance of these molecules and their links with complications. More studies should be conducted for better understanding the physiopathology, how exactly these molecules act in psoriasis and new possible therapies that decrease an unfortunate outcome.

\section{EPIDEMIOLOGY}

The recent international consensus stated that prevalence for psoriasis remains around $3 \%$ of world population, approximately 125 million people. ${ }^{3} 20-30 \%$ of the patients suffer from the severe form of the disease; of these, $10 \%$ have associated arthritis. There is no Brazilian data. Data used is based on American and European literatures. However it is known that the disease remains within low incidence.

Interracial difference is significant, affecting more Caucasians, less black people from West Africa and Asians, and sparing Indians. Regarding gender, there is no major difference between men and women concerning prevalence, but studies reveal that the

\footnotetext{
Received on 03.05.2016.

Approved by the Advisory Board and accepted for publication on 24.12.2016.

* Study conducted at the Department of Dermatology of Hospital Universitário Pedro Ernesto - Universidade do Estado do Rio de Janeiro (HUPE-UERJ) - Rio de Janeiro (RJ), Brazil.

Financial support: none.

Conflict of interest: none.

Department of Dermatology, Hospital Universitário Pedro Ernesto - Universidade do Estado do Rio de Janeiro (HUPE-UERJ) - Rio de Janeiro (RJ), Brazil. Private Clinic - Salvador (BA), Brazil.

Department of Dermatology, Centro Universitário Cesmac - Maceió (AL), Brazil.

Department of Dermatology, Centro Universitário Tiradentes (Unit) - Maceió (AL), Brazil.

(C2017 by Anais Brasileiros de Dermatologia
} 
disease starts earlier in women, around 5-9 years of age. When compared with men, its development starts between 15 and 19 years old. ${ }^{4}$ When studying the age when the disease first started to spread, it is possible to observe that it has a bimodal behavior, with a peak (75\% of the cases) before 40 and another around 55-60 years old. An earlier peak is intimately related to positive family history.

\section{GENETICS}

It has been agreed to consider polygenic and multifactorial inheritance, with environmental factors that turn on the expression of genes.

The major histocompatibility complex (MHC) is psoriasis main genetic determinant. It contains a group of genes located in the short arm of chromosome 6 . This part of genome is named human leucocyte antigen (HLA) system. Genes that codify alloantigen HLA of class I and II are linked together in the short arm of chromosome 6. Psoriasis susceptibility locus 1 (PSORS1) is an important genetic determinant to psoriasis, responsible for $50 \%$ of the disease inheritance, and is located inside MHC in class I region. This area contains at least ten genes with strong association to polymorphism and psoriasis.

The most recent analysis of genome association, reproduced in more than one study on different population, revealed or confirmed association of genic regions: IL23R, LCE3C/3D, IL13, TNIP1, IL12B, CDKAL1, HLA-C, TNFAIP3, IL23A/STAT2 and ZNF313. Although the latest data describe only part of psoriasis' cause, matching related genes can trace an important model of the disease's pathogenesis, as described: ${ }^{5}$

- Skin barrier function: DEFB, LCE3B, LCE3C

- Innate immunity NFkB, IFN

- Signaling

TNFAIP3, TN1P1, NFKBIA, REL, TYK2, IFIH1, IL23RA, MHC

- Th17 response IL12B, IL23A, IL23R, TRAF3IP2, TIK2

- Th2 response IL4, IL13

- Adaptative immunity (CD8+) ERAP1, ZAP70

\section{IMMUNOLOGY}

Clinical and experimental studies defined psoriasis as an inflammatory disease, mediated by $\mathrm{T}$ lymphocytes, with Th1 response, that affects genetically predisposed individuals after an environmental stimulus, being epidermal hyperplasia the latter result of these cells inflammatory activity. Thus, keratinocytes are no longer the villains. Recently Th17 and Th22 immune responses were also linked to triggering the disease. In humans, growth, survival and formation of functional Th17 cells depend on IL-23, TGF- $\beta$ and IL1- $\beta$ released by macrophages and dendritic cells. Th17 cells release IL-17 and IL-22 after IL-23 stimulus. ${ }^{6}$ Therefore, the predominant immune response is cellular from recognition and processing of antigens by dendritic cells. These are then presented to T lymphocytes, especially to CD4 t cells, which will release cytokines including IL2 , IFN- $\gamma$ and TNF- $\alpha$. Simultaneously, activation and proliferation of $\mathrm{T}$ cells, CD4+ and CD8+ occurs, increasing inflammatory cellular immune response. ${ }^{7}$
Antigen presenting cells act via MHC class I or II, presenting antigens to lymphocytes T CD8 and T CD4, respectively. Both lymphocyte function-associated antigen 1(LFA-1) and ICAM-1 contribute to maintenance of this cellular interaction, allowing antigen recognition and correct lymphocyte activation. Lots of biochemical signals are part of this system. These cytokines promote a cascade effect that results in epidermis and blood vessels hyperproliferation, besides proinflammatory effects. Lymphocytes release TNF- $\alpha$ and IFN $-\gamma$ and activate keratinocytes that then release IL-8, cytokine responsible for recruiting neutrophils into epidermis. ${ }^{8}$ Neutrophils, in turn, release mediators that act on endothelial cells, so they start expressing adhesion molecules. Consequently, an inflow of leukocytes is allowed into the site of inflammation and, if the situation is sustained, increase capillary permeability occurs, resulting in leakage of solutes to interstitial area, and relative hypovolemia. This condition evolves with congestion of many organs because the leaked fluid tends to return to intravascular site within treatment. This hemodynamic instability exposes the patient to an unfavorable evolution end even death.

The text above demonstrates the complexity of interactions between cells and cytokines, culminating in psoriasis. A deeper comprehension of these processes will help the development of more specific and long-lasting treatments, with less adverse events.

\section{THE DISEASE}

Psoriasis presents itself in eight clinical types, and a same patient may present more than one. They are: plaques, guttate, pustular, erythrodermic, inverse, nail and scalp psoriasis, and psoriatic arthritis. The most unstable forms are pustular and erythrodermic, that will be further discussed by their relation to systemic capillary leak syndrome. The pustular form is characterized by sterile pustules, disseminated or localized. There is a sudden onset followed by fever, poor clinical status and leukocytosis. Interruption of systemic corticosteroids, without replacing them by any other similar maintenance therapy, frequently triggers pustular psoriasis. It requires quick and effective treatment. Erythrodermic psoriasis, on the other hand, can be described when more than $80 \%$ of body surface is affected by erythema, scaling, edema with or without exudate, alopecia and nail dystrophy. ${ }^{9}$ It is followed by pruritus and interruption of daily routine, either due to indisposition or discriminatory behavior towards the patient. Its installation can be slower than the pustular form and this fact interfers directly in the organism capacity of adaptation to these changes. The more sudden it starts, the less time the organism has to adapt to hydroelectrolitic and protein losses, and it may present fever, hypotension, thermoregulatory disorder and even shock, all deriving from endothelial injuries. Thus, this condition leads to the most alarming complication of all - the systemic capillary leak syndrome, described bellow.

\section{SYSTEMIC CAPILLARY LEAK SYNDROME}

Also known as leak syndrome, it is rare and caused by the increase of capillary permeability. This results in accumulation of fluids and protein in the interstitial or extravascular sites, followed by a subsequent hypovolemic shock. ${ }^{10}$ It is a severe and potentially fatal condition if not managed correctly. It is more prevalent be- 
tween the fourth and fifth decades of life and both men and women are affected. ${ }^{11}$

There are three types of this syndrome: idiopathic, drug-induced and associated to skin diseases, commonly erythrodermic and pustular psoriasis. ${ }^{12-14}$ Mechanism that helps increase capillary permeability are not yet clear, but many hypothesis were studied:

-IL-2 and 6, IFN- $\gamma$ and TNF- $\alpha$ would cause endothelial injury;

- Leukotriene B4 acts over capillary permeability, since its accumulation was detected in vitro ${ }^{15}$;

Endothelial cells apoptosis caused by increase of nitric oxide, generated in the serum of patients with the syndrome;

Elevation of VEGF in patients that present large skin injuries, inducing even more leak through microvasculature (general pustular psoriasis is followed by high levels of VEGF, produced by psoriatic plaques) ${ }^{16}$

The syndrome has three phases but, when related to skin lesions, the first phase - prodromal phase - is absent. During the second and acute phase there is loss of water, electrolytes and protein to the extravascular site, with edema, compartment syndrome, weight gain, erythema, pruritus, sudoresis, kidney failure and hypovolemic shock. ${ }^{17}$ During the third phase, called late or plasmatic expansion, the fluid returns to intravascular space and is responsible for causing acute pulmonary edema, respiratory distress syndrome in adults, pericardial effusion, cardiac tamponade and cardiogenic shock. Severe hypoxia associated with pulmonary congestion and normal cardiac function occurs. Major complications that endanger patients' lives occur in this phase. ${ }^{18}$ Hypoalbuminemia, neutrophilia and hemoconcentration are detected in laboratory tests, what limits the efficiency of plasma expanders.

In the erythrodermic form, daily protein loss of about 25$30 \%$ causes edema, weakness and hypoalbuminemia. There is compensatory hyperactive metabolism and increased basal metabolic rate. Heat losses through the dilated permeable capillaries accelerates blood flow and may cause hypothermia. The inability to respond with vasoconstriction and/or vasodilation maintains this temperature change. It can be fatal, especially for elderly and people with cardiovascular diseases.

Diagnostic and therapeutic approaches are fundamental for promptly noticing the risks and their prevention. The patient must be hospitalized for clinical observation, cautious venous hydration, environment with controlled temperature and humidity, and adequate nutrition, needing intensive care in some cases. ${ }^{19}$ Among the required exams are serum protein, calcium, urea and creatinine, in addition to infectious and inflammatory markers. This literature review aims to clarify the relevance of VEGF and ICAM-1 measurement, so they can act as predictors of clinical management and outcome, anticipating treatment and avoiding evolution to endothelial damage. As they have more evidence of being involved in psoriasis pathogenesis, both will be better discussed next, considering VEGF the primary angiogenic factor in this process. ${ }^{20}$

Among treatments, the following have been reported: systemic treatment with corticosteroids, when the cause for the dermatitis is unknown or, when it is psoriasis, but associated with respiratory distress syndrome in adults or pulmonary edema. Cyclosporine takes place when the etiology is unstable psoriasis (erythrodermic or pustular), without respiratory distress. ${ }^{21}$ Some options are under study, such as medications that inhibit VEGF or its pathways.

\section{VASCULAR ENDOTHELIAL GROWTH FACTOR (VEGF)}

It is a glycoprotein released in the vascular wall by the endothelium and by straight muscles cells, with varied consequences to the endothelium. ${ }^{22}$ Among its functions, it makes venules hyper permeable to macromolecules, creates accumulation of cytoplasmic calcium, cell division and migration, and induces angiogenesis. ${ }^{23}$ It has two high-affinity receptors in the vascular endothelium, both transmembrane proteins. ${ }^{24}$ Where there is overexpression of VEGF, the expression of receptors also increases in adjacent endothelial cells. One of those places is the dermis of psoriasis patients. There are extensive evidences indicating that vascular hyperpermeability controls, conducts or even precedes angiogenesis. VEGF acts by permeabilizing many different vascular beds, such as skin, mesentery, and diaphragm. This substance has its expression increased during important non-neoplastic diseases, characterized by angiogenesis. In these cases, it seems that capillaries are hyperpermeable as in psoriasis, rheumatoid arthritis and wound healing process. ${ }^{25}$ This manifestation occurs through TGF- $\alpha$ (transformation growth factor) and EGF (epidermal growth factor) acting over keratinocytes and macrophages, which begin overexpressing VEGF, with its plasmatic concentration related to the extent of the skin injuries. Therefore, over expression of VEGF and its receptors, in addition to extravascular deposition of fibrin, conduct angiogenesis in psoriasis and responds accordingly to the lesions status. ${ }^{20}$ As reported before, in pustular psoriasis, VEGF is in high levels and produced by the plaques. Numerous antiangiogenic substances have been reported by literature, such as corticosteroid, thalidomide and tumor necrosis factor-alpha inhibitors. ${ }^{23,26}$

\section{INTERCELLULAR ADHESION MOLECULE (ICAM-1)}

It is a member of an immunoglobulin superfamily, necessary for leucocytes adherence to capillary endothelium. ${ }^{27}$ It has an important role in recruiting and retaining proinflammatory cells. Leucocytes activation, circulation and migration to inflammatory sites depend on this molecule. TNF- $\alpha$, together with interleukin 1 and reactive $C$ protein, is the main responsible for expressing this molecule to endothelium, macrophages and lymphocytes, via protein kinase $\mathrm{C}$ activation. ${ }^{28}$ When TNF- $\alpha$ is presented in high levels, ICAM-1 begins allowing that lymphocytes link to endothelium and migrate to the tissue, leading to microvascular hyperpermeability. These events allow the transfer of solutes to peripheral tissues. ${ }^{29}$ As a result, there is an alteration in albumin transport during inflammatory process and its journey is influenced by TNF- $\alpha$ and ICAM-1.

\section{CONCLUSION}

Studies that evaluate skin and blood levels of VEGF and ICAM-1 in psoriasis patients are necessary in order to have their relevance recognized, correlating the levels of these substances with the disease's importance and subtypes and, possibly, influencing new treatments. $\square$ 


\section{REFERENCES}

1. Kerkhof PCM, Schalkwijk J. Psoriasis. In: Bolognia JL, Jorizzo JL, Rapini RP, editors. Dermatology. St., Louis: Mosby Elsevier; 2008. p.9: 115-135.

2. Bressan AL, Gripp A, Fontenelle EO, Souto RS. Síndrome de extravasamento capilar sistêmico. An Bras Dermatol. 2011;86:593-5.

3. Psoriasis.org [Internet]. National Psoriasis Foundation. Anderson K. People of all races overcome psoriatic disease. [cited 2016 May 05]. Available from: www. psoriasis.org/advance/features/people-of-all-races-overcome-the-challenge-ofpsoriatic-diseases.

4. Holgate MC. The age of onset of psoriasis. Br J Dermatol. 1975;92:443-448.

5. Magalhães RF. Genética. In: Romiti R. Compêndio de psoríase. 2 ed. Rio de Janeiro: Elsevier; 2013. p.4:23-40.

6. Ortigosa LCM, Silva LCR, Benard G. Imunologia. In: Romiti R. Compêndio de psoríase. 2. ed. Rio de Janeiro: Elsevier; 2013. p.5:41-50.

7. Sabat R, Philipp S, Höflich C, Kreutzer S, Wallace E, Asadullah K, et al. Immunopathogenesis of psoriasis. Exp Dermatol. 2007;16:779-98.

8. Tonel G, Conrad C. Interplay between keratinocytes and imune cells-recent insights into psoria-sis pathogenesis. Int J Biochem Cell Biol. 2009;41:963-8.

9. Fabricio L. Psoríase eritrodérmica. In: Romiti R. Compêndio de psoríase. 2. ed. Rio de Janeiro: Elsevier; 2013. p.9: 75-78

10. Amoura Z, Papo T, Ninet J, Hatron PY, Guillaumie J, Piette AM, et al. Systemic capillary leak syndrome: report on 13 patients with special focus on course and treatment. Am J Med. 1997;103:514-9.

11. Dhir V, Arya V, Malav IC, Suryanarayanan BS, Gupta R, Dey AB. Idiopathic systemic capil-lary leak syndrome: case report and systematic review of cases reported in the last 16 years. Intern Med. 2007:46:899-904.

12. Vos LE, Vermeer MH, Pavel S. Acitretin induces capillary leak syndrome in a patient with pus-tular psoriasis. J Am Acad Dermatol. 2007; 56:339-42.

13. Barnadas MA, Cisteró A, Sitjas D, Pascual E, Puig X, de Moragas JM. Systemic capillary leak syndrome. J Am Acad Dermatol. 1995;32:364-6.

14. Gripp AC, Jaime TJ, Stolarczuk DA, Dantas MM, Miranda CVR. Síndrome de extravasamento capilar como complicação da psoríase eritrodérmica e seu difícil manejo. Pôster apresentado no 63. Congresso Brasileiro de Dermatologia da Sociedade Brasileira de Dermatologia; 2008 set 6-10; Fortaleza, Ceará.

15. Vigneau C, Haymann JP, Khoury N, Sraer JD, Rondeau E. An unusual evolution of the system-ic capillary leak syndrome. Nephrol Dial Transplant. 2002;17:492-4.

16. Creamer D, Allen M, Jaggar R, Stevens R, Bicknell R, Barker J. Mediation of systemic vascular hipermeability in severe psoriasis by circulating vascular endothelial growth factor. Arch Dermatol. 2002;138:791-6.
17. Bonadies N, Baud P, Peter HJ, Buergi U, Mueller BU. A case report of Clarkson's disease: If you don't know it, you'll miss it. Eur J Intern Med. 2006;17:363-5

18. Tahirkheli NK, Greipp PR. Systemic capillary leak syndrome. Long-term follow up. Ann Intern Med. 1999;130:905-9.

19. Gripp A, Carvalho AVE, Cursi IB, Souza CS. Manejo do paciente grave internado In: Consenso Brasileiro de Psoríase: guias de avaliação e tratamento. Sociedade Brasileira de Dermatologia. 2. ed. 2012. p.18:159-163.

20. Meki AR, Al-Shobaili H. Serum vascular endotelial growth fator, transforming growth fator $\beta 1$, and nitric oxide levels in patients with psoriasis vulgaris: their correlation to disease severity. J Clin Lab Anal. 2014;28:496-501.

21. Bressan AL, Silva RS, Fontenelle E, Gripp AC. Imunossupressores na Dermatologia. An Bras Dermatol. 2010;85:9-22.

22. Alves CMP, Teixeira MCB, De Martino MC. Dosagem de marcadores de lesão endotelial em pacientes com doença renal crônica em hemodiálise. J Bras Patol Med Lab. 2010;46:207-14.

23. Xie Z, Ghosh CC, Patel R, Iwaki S, Gaskins D, Nelson C, et al. Vascular endothelial hyperpermeability induces the clinical symptoms of Clarkson disease (the systemic capillary leak syndrome). Blood. 2012;119:4321-32.

24. Canavese M, Altruda F, Ruzicka T, Schauber J. Vascular endothelial growth factor (VEGF) in the pathogenesis of psoriasis - a possible target for novel therapies? J Dermatol Sci. 2010;58:171-6.

25. Dvorak HF, Brown LF, Detmar M, Dvorak AM. Vascular permeability factor/vascular endothelial growth factor, microvascular hyperpermeability, and angiogenesis. AJP. 1995; 146:1029-39.

26. Dias PF, Ribeiro-do-Valle RM, Maraschim RP, Maraschim M. Novos moduladores da formação de vasos sanguíneos. Biotecnologia, Ciência e Desenvolvimento. 2002:25:28-34.

27. Jain A, Saxena S, Khanna VK, Shukla RK, Meyer CH. Status of serum VEGF and ICAM-1 and its association with external limiting membrane and inner segment outer segment junction disruption in type 2 diabetes mellitus. Mol Vis. 2013;19:1760-8.

28. Dowlatshahi EA, van der Voort EA, Arends LR, Nijsten T. Markers of systemic inflammation in psoriasis: a systematic review and meta-analysis. Br J Dermatol. 2013:169:266-82.

29. Frank PG, Lisanti MP. ICAM-1: role in inflammation and in the regulation of vascular permeability. Am J Physiol Heart Circ Physiol. 2008;295:H926-H927.

\author{
MAILING ADDRESS: \\ Aline Lopes Bressan \\ Boulevard 28 de Setembro, 77 \\ Vila Isabel \\ 20551-030 Rio de Janeiro, RJ. \\ Brazil \\ E-mail:alinebressan@ig.com.br
}

How to cite this article: Bressan AL, Pereira D, Medeiros PM, Carneiro S, Azulay-Abulafia L. How relevant are vascular endothelial growth factor and intercellular adhesion molecule in the systemic capillary leak syndrome of psoriasis? An Bras Dermatol. 2017;92(6): 826-9. 